\title{
Carboplatin/Trastuzumab Regimen
}

National Cancer Institute

\section{Source}

National Cancer Institute. Carboplatin/Trastuzumab Regimen. NCI Thesaurus. Code C156373.

A chemotherapy regimen consisting of carboplatin and trastuzumab that may be used for the treatment of HER-2 (EGFR2; ErbB2)-positive breast cancer. 